\title{
THE
}

\section{Four Current Meter Models Compared in Strong Currents in Drake Passage}

D. Randolph Watts

University of Rhode Island, randywatts@uri.edu

Maureen A. Kennelly

University of Rhode Island, mkennelly@uri.edu

Kathleen A. Donohue

University of Rhode Island, kdonohue@uri.edu

Karen L. Tracey

University of Rhode Island, krltracey@uri.edu

Teresa K. Chereskin

See next page for additional authors

Follow this and additional works at: https://digitalcommons.uri.edu/gsofacpubs

\section{Citation/Publisher Attribution}

Watts, D. R., Kennelly, M. A., Donohue, K. A., Tracey, K. L., Chereskin, T. K., Weller, R. A., \& Victoria, I. (2013). Four Current Meter Models Compared in Strong Currents in Drake Passage. Journal of Atmospheric and Oceanic Technology, 30, 2465-2477. doi: 10.1175/JTECH-D-13-00032.1

Available at: http://dx.doi.org/10.1175/JTECH-D-13-00032.1

This Article is brought to you for free and open access by the Graduate School of Oceanography at DigitalCommons@URI. It has been accepted for inclusion in Graduate School of Oceanography Faculty Publications by an authorized administrator of DigitalCommons@URI. For more information, please contact digitalcommons-group@uri.edu. 


\section{Authors}

D. Randolph Watts, Maureen A. Kennelly, Kathleen A. Donohue, Karen L. Tracey, Teresa K. Chereskin, Robert A. Weller, and Ivan Victoria

This article is available at DigitalCommons@URI: https://digitalcommons.uri.edu/gsofacpubs/525 


\title{
Four Current Meter Models Compared in Strong Currents in Drake Passage
}

\author{
D. Randolph Watts, Maureen A. Kennelly, Kathleen A. Donohue, \\ AND KAREN L. TRACEY \\ Graduate School of Oceanography, University of Rhode Island, Narragansett, Rhode Island \\ TERESA K. CHERESKIN \\ Scripps Institution of Oceanography, University of California, San Diego, La Jolla, California \\ ROBERT A. WELLER \\ Woods Hole Oceanographic Institution, Woods Hole, Massachusetts \\ IVAN VICTORIA \\ Aanderaa Data Instruments, Inc., Attleboro, Massachusetts
}

(Manuscript received 15 February 2013, in final form 11 June 2013)

\begin{abstract}
Seven current meters representing four models on a stiffly buoyed mooring were placed for an 11-month deployment to intercompare their velocity measurements: two vector-measuring current meters (VMCMs), two Aanderaa recording current meter (RCM) 11s, two Aanderaa SEAGUARDs, and a Nortek Aquadopp. The current meters were placed 6-m apart from each other at about 4000-m depth in an area of Drake Passage expected to have strong currents, nearly independent of depth near the bottom. Two high-current events occurred in bursts of semidiurnal pulses lasting several days, one with peak speeds up to $67 \mathrm{~cm} \mathrm{~s}^{-1}$ and the other above $35 \mathrm{~cm} \mathrm{~s}^{-1}$. The current-speed measurements all agreed within $7 \%$ of the median value when vector averaged over simultaneous time intervals. The VMCMs, chosen as the reference measurements, were found to measure the median of the mean-current magnitudes. The RCM11 and SEAGUARD current speeds agreed within $2 \%$ of the median at higher speeds $\left(35-67 \mathrm{~cm} \mathrm{~s}^{-1}\right)$, whereas in lower speed ranges $\left(0-35 \mathrm{~cm} \mathrm{~s}^{-1}\right)$ the vector-averaged speeds for the RCM 11 and SEAGUARD were $4 \%-5 \%$ lower and $3 \%-5 \%$ higher than the median, respectively. The shorter-record Aquadopp current speeds were about $6 \%$ higher than the VMCMs over the range $\left(0-40 \mathrm{~cm} \mathrm{~s}^{-1}\right)$ encountered.
\end{abstract}

\section{Introduction}

We report here the results of an opportunity to compare current measurements from three different-model acoustic Doppler single-height current meters [Aanderaa recording current meter (RCM) 11, Aanderaa SEAGUARD, and Nortek Aquadopp] and the vectormeasuring current meter (VMCM), whose accuracy has been previously characterized by tow tank tests (Weller and Davis 1980). This new comparison was conducted on a moored deployment because for acoustic Doppler

Corresponding author address: D. Randolph Watts, Graduate School of Oceanography, University of Rhode Island, 215 South Ferry Road, Narragansett, RI 02882.

E-mail: randywatts@mail.uri.edu current sensors, a calibration test in a tow tank was not suitable because of acoustic reflections off the sidewalls. Our chief aim was to obtain comparisons at speeds in excess of $35 \mathrm{~cm} \mathrm{~s}^{-1}$ to determine if a speed-correction factor should be applied to the speeds recorded by current- and pressure-equipped inverted echo sounders (CPIES), which use the RCM11 Doppler current meter head during the cDrake experiment (Chereskin et al. 2009). Previous tests by Hogg and Frye (2007), in conditions with current speeds less than about $35 \mathrm{~cm} \mathrm{~s}^{-1}$, found that the RCM11 recorded consistently lower speeds than vector-averaging and vector-measuring current meters. Subsequently in a comparison conducted in the Kuroshio Extension region, the bias remained at low speeds but appeared to lessen for speeds near $40 \mathrm{~cm} \mathrm{~s}^{-1}$ (N. Hogg 2007, personal communication). During the 


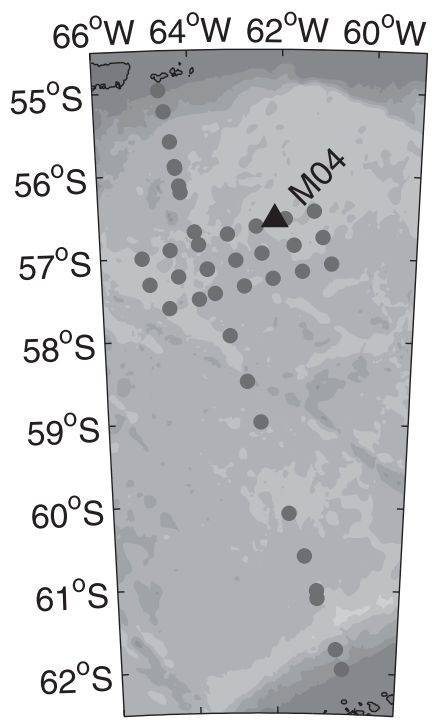

FIG. 1. Location of M04 in the cDrake array is indicated by the black triangle. Gray circles indicate the locations of CPIES sites. Bathymetry derives from Smith and Sandwell (1997) with contours every 1000-m depth: dark gray hues represent shallow depths and they transition to light gray hues in the deeper parts of the passage. See Chereskin et al. (2009) for details of the cDrake experiment.

first-year (2007-08) deployment in cDrake (http://www. cDrake.org), RCM11 current meter heads located 50-m above the seafloor on CPIES observed several highspeed current events with peak speeds of $60-70 \mathrm{~cm} \mathrm{~s}^{-1}$ typically lasting a week or more. These observations were within a $3 \times 7$ array of sites in the northern Drake Passage situated in a local maximum of surface eddy kinetic energy between the Subantarctic and Polar Fronts. Furthermore, we had begun to use newer Aanderaa SEAGUARDs on CPIES, and we were concerned to test whether speed biases might exist in that current meter model.

A short near-bottom mooring, designated M04 in the cDrake local dynamics array, was deployed for one year (Fig. 1). The site was chosen where weak stratification indicated near-bottom vertical shear should be negligible, with the expectation that all current meters would observe the same current. Other advantages of conducting this comparison in the deep ocean were (i) that a short deep mooring could be designed to reduce tilt and mooring motion expected in high currents, and (ii) it would avoid near-surface hazards such as biofouling, ice, and fishing/trawling activities.

Several previous studies intercompared current meters, generally in environments with current speeds below $35 \mathrm{~cm} \mathrm{~s}^{-1}$. A broad review of modern current measuring techniques is given in Dickey et al. (1998). Hogg and Frye (2007) compared acoustic current meters against vectoraveraging current meters (VACMs) and VMCMs on deep subsurface moorings and on shipboard lowerings of a CTD system. Those moored tests indicated that the RCM11 speeds appeared to have a systematic low bias relative to those of the VMCM and VACM by about $10 \%$. However, a low RCM11 bias was not apparent in the noisier comparison of the CTD-lowered instruments for speeds of about $25 \mathrm{~cm} \mathrm{~s}^{-1}$.

A. Houk and W. Johns (2012, unpublished manuscript) compared data from three different models of single-point acoustic Doppler current meters [a Nortek deep-water Aquadopp, a Teledyne RD Instruments Doppler Volume Sampler (DVS), and an Aanderaa SEAGUARD] from an 18-month deployment (December 2009-April 2011). They found that differences between measurements were close to expected uncertainties, but they also found a slight bias in speed and direction in the Aquadopp compared to the DVS and SEAGUARD. The bias increased slightly with increasing current speed. The results of several recent intercomparison studies with SEAGUARDs are summarized in Victoria (2011).

\section{Mooring description}

Our mooring design used established procedures and hardware components, plus specialized low-drag buoyancy. We sought a balance between

(i) placing instruments more than $3 \mathrm{~m}$ apart to avoid spurious sidelobe acoustic reflections off mooring components and with at least $5 \mathrm{~m}$ of wire between them to enable individual handling during launch and recovery, and

(ii) achieving minimal mooring motion and tilt in strong currents by using short wire lengths and low-drag components.

Seven current meters representing four different models, nominally separated by $6 \mathrm{~m}$, were on the mooring: two Aanderaa RCM11s, two Aanderaa SEAGUARDs, two VMCMs and one Nortek deep-water Aquadopp (Fig. 2). A summary of manufacturer's specifications for the four model types is given in Table 1 . We chose to compare same models with and without enabling internal correction of the current for tilt of the current meter.

Below the mooring flotation, the RCM11s were located at levels 1 (no tilt correction) and 4 (tilt correction), the VMCMs at levels 2 and 6, the SEAGUARDs at levels 3 (tilt correction) and 5 (no tilt correction), and the Aquadopp at level 7. Their heights ranged from 98 to $136 \mathrm{~m}$ above the seafloor to avoid the benthic boundary layer (BBL). Details of a BBL thickness estimate of $67 \mathrm{~m}$ are presented in Kennelly et al. (2012), and no systematic differences between the current meter observations were evident that could be consistent with a 


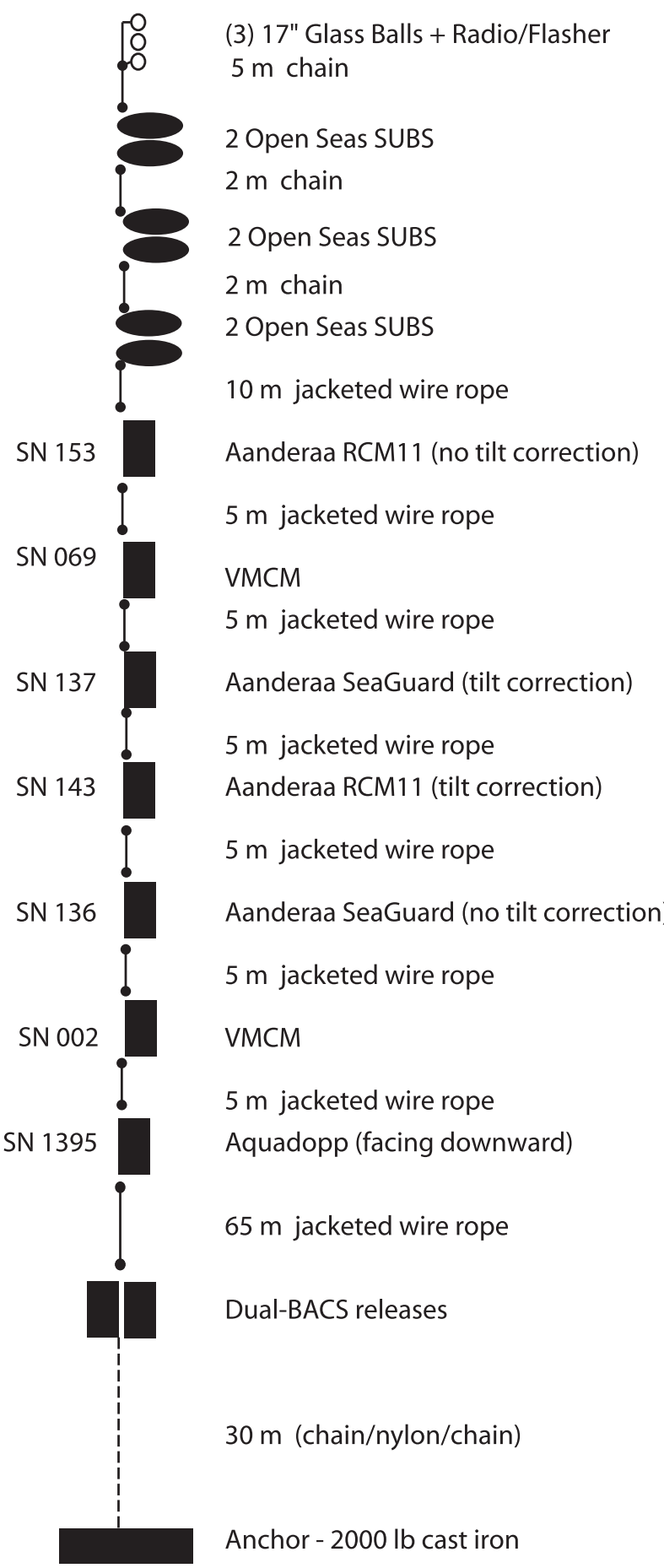

FIG. 2. Mooring schematic

BBL influence. The mooring was deployed and recovered from the Research Vessel/Icebreaker (RV/IB) Nathaniel B. Palmer, and collected data from November 2009 to October 2010 in approximately $4000 \mathrm{~m}$ at $56.55^{\circ} \mathrm{S}$, $62.15^{\circ} \mathrm{W}$.
Each current meter model type allows multiple configuration options. Our goal was to configure the instruments similarly, yet there were differences. All acoustic-type current meters were set to record samples at 30-min intervals. The sampling interval for the VMCMs was $1 \mathrm{~min}$. Sampling methods and averaging intervals are, however, different for model types: the VMCMs and RCM11s spread sampled, while the SEAGUARDs and Aquadopp were configured for burst-mode sampling. The VMCMs computed east and north components of velocity nearly continuously and averaged over $1 \mathrm{~min}$. The RCM11s transmitted 600 evenly distributed pings over the 30-min sampling interval. The SEAGUARDs transmitted 300 pings in the last $60 \mathrm{~s}$ of the 30 -min sampling interval. The Aquadopp was set to ping at $0.92 \mathrm{~Hz}$ for $2 \mathrm{~min}$, giving 110 pings per ensemble at the start of each 30-min interval. Battery life dictated our choice of different ping rates (Kennelly et al. 2012). The Aquadopp settings predicted a 13-month lifetime. We mistakenly chose too high a ping rate (600 pings) for the RCM11, and their batteries depleted (as could have been predicted) after 295 days. The RCM11 and SEAGUARD used a fixed sound speed of $1500 \mathrm{~m} \mathrm{~s}^{-1}$, while the Aquadopp calculated sound speed from temperature for each sample. Further details about instrument configuration for this deployment are provided in Kennelly et al. (2012). Given the different sampling methods and averaging intervals, careful analyses discussed in section 3 were required to make direct comparisons among these four models of current meters.

Because of the stiff mooring design, recorded tilts were less than $15^{\circ}$ during typical currents of $<20 \mathrm{~cm} \mathrm{~s}^{-1}$ and ranged from $10^{\circ}$ to $26^{\circ}$ at the highest-to-lowest current meters at the highest speeds $\left(67 \mathrm{~cm} \mathrm{~s}^{-1}\right)$. The largest drawdown of the mooring ( $\sim 45 \mathrm{~m})$, as recorded by the SEAGUARD pressure records, occurred during the highest current event between days 565 and 572. In four other events, the drawdown was $20 \mathrm{~m}$, but in most events the drawdown was less than $10 \mathrm{~m}$.

\section{Data return and processing}

Current measurements were made during a 337-day period from 24 November 2009 to 28 October 2010 with the VMCMs and SEAGUARDs (Fig. 3). Because of depleted batteries, the Aquadopp data record ended in June 2010 and the two RCM11 records ended in September. The batteries may have been subjected to high temperatures during shipping. A 198-day period is common to all model types. Current speeds were typically less than $20 \mathrm{~cm} \mathrm{~s}^{-1}$. Two strong-current intervals occurred; the highest event with instantaneous speeds exceeding $67 \mathrm{~cm} \mathrm{~s}^{-1}$ lasted for 7 days (days 565-572). 
TABLE 1. Current meter manufacturer's specifications. Further information for the SEAGUARD and Aquadopp can be found online (www.aanderaa.com/media/pdfs/SeaGuard-RCM.pdf and www.nortekusa.com/lib/data-sheets/datasheet-aquadopp-6000m).

\begin{tabular}{|c|c|c|c|c|}
\hline & RCM11 & VMCM & SEAGUARD & Aquadopp \\
\hline $\begin{array}{l}\text { Manufacturer } \\
\text { Firmware } \\
\text { Current speed }\end{array}$ & $\begin{array}{c}\text { Aanderaa } \\
-\end{array}$ & $\begin{array}{l}\text { WHOI } \\
\text { VMCM2, version } 3.10\end{array}$ & $\begin{array}{l}\text { Aanderaa } \\
1.4 .33\end{array}$ & $\begin{array}{l}\text { Nortek } \\
1.21\end{array}$ \\
\hline $\begin{array}{l}\text { Type } \\
\text { Range }\left(\mathrm{cm} \mathrm{s}^{-1}\right) \\
\text { Accuracy }\left(\mathrm{cm} \mathrm{s}^{-1} ; \%\right) \\
\text { Resolution }\left(\mathrm{cm} \mathrm{s}^{-1}\right) \\
\text { Direction }\end{array}$ & $\begin{array}{l}\text { Acoustic (Doppler) } \\
0-300 \\
\pm 0.15 \text { or } \pm 1 \% \\
0.3\end{array}$ & $\begin{array}{l}\text { Mechanical } \\
2-400 \\
\pm 1 \% \\
0.17\end{array}$ & $\begin{array}{l}\text { Acoustic (Doppler) } \\
0-300 \\
\pm 0.15 \text { or } \pm 1 \% \\
0.01\end{array}$ & $\begin{array}{l}\text { Acoustic (Doppler) } \\
0-300 \\
\pm 0.5 \text { or } \pm 1 \% \\
0.01\end{array}$ \\
\hline Type & Hall element compass & Flux gate & $\begin{array}{l}\text { Three axis, solid state, } \\
\text { magneto resistor }\end{array}$ & Magnetometer \\
\hline $\begin{array}{l}\text { Model } \\
\text { Accuracy }\left({ }^{\circ}\right)\end{array}$ & $\begin{array}{l}- \\
\pm 5(0-15 \text { tilt }) \\
\pm 7(15-35 \text { tilt })\end{array}$ & $\begin{array}{l}\text { TCM2-20 } \\
\pm 3\end{array}$ & $\begin{array}{l}- \\
\pm 5(0-15 \text { tilt }) \\
\pm 7.5(15-35 \text { tilt })\end{array}$ & $\begin{array}{l}\text { Nortek } \\
\pm 2(\text { tilt }<20)\end{array}$ \\
\hline $\begin{array}{l}\text { Resolution }\left(^{\circ}\right) \\
\text { Temperature }\end{array}$ & 0.35 & \pm 0.1 & 0.01 & 0.1 \\
\hline $\begin{array}{l}\text { Type } \\
\left({ }^{\circ} \mathrm{C}\right) \\
\text { Accuracy }\left({ }^{\circ} \mathrm{C}\right) \\
\text { Resolution }\left({ }^{\circ} \mathrm{C}\right) \\
\text { Dimensions } \\
\end{array}$ & $\begin{array}{l}\text { Thermistor } \\
\text { from }-3.01 \text { to } 5.92 \text {, Arctic } \\
\pm 0.05 \\
(0.1 \% \text { of range })\end{array}$ & $\begin{array}{l}- \\
-\end{array}$ & $\begin{array}{l}\quad- \\
\text { from }-4 \text { to } 36 \\
\pm 0.03 \\
0.001\end{array}$ & $\begin{array}{l}\text { Thermistor } \\
\text { from }-4 \text { to } 40 \\
0.1 \\
0.01\end{array}$ \\
\hline $\begin{array}{l}\text { Length }(\mathrm{mm}) \\
\text { Weight }(\mathrm{kg})\end{array}$ & $\begin{array}{l}595 \\
26.5\end{array}$ & $\begin{array}{l}2560 \\
34.5\end{array}$ & $\begin{array}{l}368 \\
15.7\end{array}$ & $\begin{array}{l}625 \\
7.6\end{array}$ \\
\hline
\end{tabular}

A series of corrections was applied to the raw data as described in Kennelly et al. (2012). First, clock drifts ranging from 2 to $8 \mathrm{~min}$ were corrected for all but the SEAGUARDs that did not drift more than a few seconds. Four additional corrections were then applied to the records: (i) a sound speed factor was applied to Doppler current meters that otherwise used a constant sound speed (RCM11 and SEAGUARD); (ii) a tilt correction was applied to those sensors that did not internally correct for tilt (RCM11 153, SEAGUARD 136,

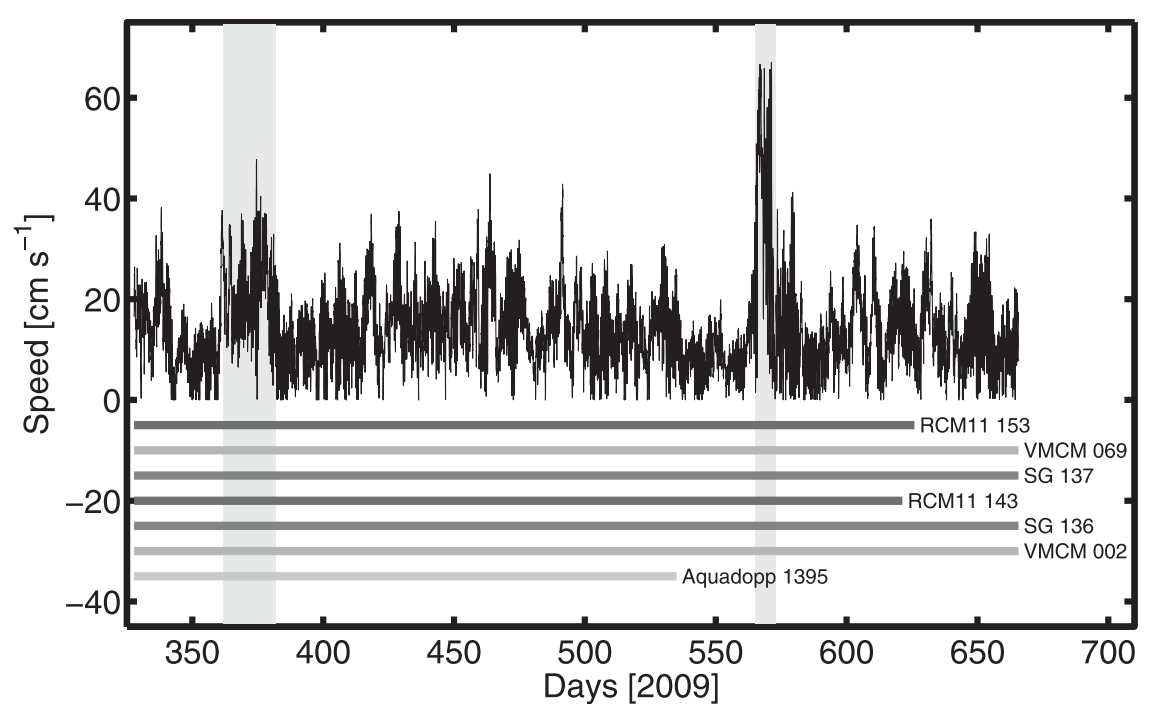

FIG. 3. (top black line) Time series of VMCM 069 speed $\left(\mathrm{cm} \mathrm{s}^{-1}\right)$. (bottom) Length of data records for individual current meters. The lines are plotted in order of vertical level on the mooring. Shading indicates two high-speed events lasting 21 (days 361-382) and 7 (days 565572) days, respectively. 
TABLE 2. Measurement noise levels. NSD is obtained from the high-frequency "tails" of the spectra. SN indicates serial number.

\begin{tabular}{clcccc}
\hline \hline Level & \multicolumn{1}{c}{ Type } & $\mathrm{SN}$ & $\begin{array}{c}\mathrm{NSD} \\
\left(\mathrm{cm}^{2} \mathrm{~s}^{-2} \mathrm{~h}^{-1}\right)\end{array}$ & $\begin{array}{c}\mathrm{EKE}_{<3 \mathrm{~h}} \\
\left(\mathrm{~cm}^{2} \mathrm{~s}^{-2}\right)\end{array}$ & $\begin{array}{c}\text { Internal tilt } \\
\text { correction }\end{array}$ \\
\hline 1 & RCM11 & 153 & 0.45 & 0.44 & No \\
2 & VMCM & 069 & 0.30 & 0.33 & No \\
3 & SEAGUARD & 137 & 0.45 & 0.45 & Yes \\
4 & RCM11 & 143 & 0.45 & 0.45 & Yes \\
5 & SEAGUARD & 136 & 0.45 & 0.46 & No \\
6 & VMCM & 002 & 0.30 & 0.33 & No \\
7 & Aquadopp & 1395 & 0.70 & 0.67 & Yes \\
\hline
\end{tabular}

and the VMCMs); (iii) the VMCM data were 30-min low-pass filtered; and (iv) all data were synchronized and interpolated to a common time base.

The RCM11 and SEAGUARD current speeds were scaled larger by a constant mean sound-speed correction ratio $\left(1521 / 1500 \mathrm{~m} \mathrm{~s}^{-1}\right)$. This factor, $1.014 \pm 0.001$, was determined from the temporal-mean Aquadopp sound speed and is consistent with CTD casts taken at the beginning and end of the mooring deployment.

Current speeds for the sensors that did not internally record tilt were scaled by $(1 / \cos \phi)$, where the tilt magnitude $\phi$ was calculated as

$$
\phi=\arctan \sqrt{\tan ^{2}\left(\operatorname{tilt}_{x}\right)+\tan ^{2}\left(\operatorname{tilt}_{y}\right)},
$$

where tilt $x_{x}$ and tilt $y$ are tilts on two axes recorded by the current meters. Internal tilt correction was turned off for RCM11 153 and SEAGUARD 136. Although RCM11s can be configured for internal tilt correction, they do not record tilt. We used $\phi$ calculated at level 2 for VMCM 069 to correct RCM11153 at level 1.

To facilitate intercomparison, it was necessary to synchronize the zonal $u$ and meridional $v$ velocity time bases. Recorded time stamps were shifted to correspond to the midpoints of the respective averaging intervals for each model type. Finally, the records for all models were interpolated to a common set of 30-min intervals at 0 - and 30-min UTC after the hour.

The measurement noise levels of the instruments, listed in Table 2, were estimated two ways: (i) using spectra to estimate the level at which the high-frequency portion goes white and (ii) calculating the variance $\left(\overline{u^{\prime 2}}+\overline{v^{2}}\right) / 2$ of the 3 -h high-pass-filtered records. These numbers give a useful velocity standard deviation, as follows. If one integrates the noise spectral density (NSD)-for example, $0.45 \mathrm{~cm}^{2} \mathrm{~s}^{-2} \mathrm{~h}^{-1}$ in Table 2-over the frequency band from $1 / 3 \mathrm{~h}$ to the Nyquist-1/0.5 $\mathrm{h}$-then one gets a velocity standard deviation of $\sqrt{0.45(2-0.333)}=0.9 \mathrm{~cm} \mathrm{~s}^{-1}$. We determined that for each of the two pairs of same-model instruments, the noise floor was the same regardless of whether the tilt correction was done internally or calculated in postprocessing. To compare their noise variance, which appeared to be isotropic, all the records were 3-h highpass filtered and their eddy kinetic energy $\mathrm{EKE}_{<3 \mathrm{hr}}$ is tabulated in Table 2. The VMCMs had the lowest noise floor. The RCM11s and SEAGUARDs have somewhat higher noise floors, and the Aquadopp had the highest (which may have been due to its battery-constrained lower number of pings).

While outside the scope of this paper, the temperature and pressure records of several instruments were of good quality and are presented in Kennelly et al. (2012).

\section{Comparisons}

We report on results of three different comparison methods here: vector averaging, linear regression analysis, and response analysis of $u$ and $v$ components. The comparisons were done for same- and different-model pairs. For the different-model pair comparisons, we chose one representative from each current meter model. The instruments chosen were VMCM 069, RCM11153, SEAGUARD 136, and Aquadopp 1395. VMCM 069 was chosen because the compass of VMCM 002 differed from the other instruments. While either RCM11 or SEAGUARD was suitable for further intercomparison between models, we chose RCM11 153 and SEAGUARD 136 for which tilt corrections were postprocessed consistently with VMCM 069.

\section{a. Vector averaging}

During the 198-day period common to all instruments (days 327-525), mean-current speeds (i.e., vector-mean magnitudes) were approximately $9 \mathrm{~cm} \mathrm{~s}^{-1}$ directed to the northwest (Fig. 4a and Table 3). The northwest direction arises from a broad cyclonic deep recirculation (Chereskin et al. 2009; Ferrari et al. 2012). The VMCM, SEAGUARD, and RCM11 pairs recorded mean speeds that agreed within $2 \%$ with their same-model partner. The two VMCMs recorded the median speed among the seven current meters. The two SEAGUARD mean speeds were about $5 \%$ higher than the median. The two RCM11 mean speeds were about 5\% lower than the median. The Aquadopp mean-current speed was higher than the median by about $7 \%$.

The current direction of the Aquadopp and VMCM 069 were turned $6^{\circ}$ and $3^{\circ}$, respectively, to the left of the median of all the current meters. The direction for VMCM 002 was turned about $8^{\circ}$ to the right of the median. The RCM11 and SEAGUARD pairs recorded mean directions that agreed within $1^{\circ}$ of their same-model partner, and all four clustered within $2^{\circ}$ of the median. 

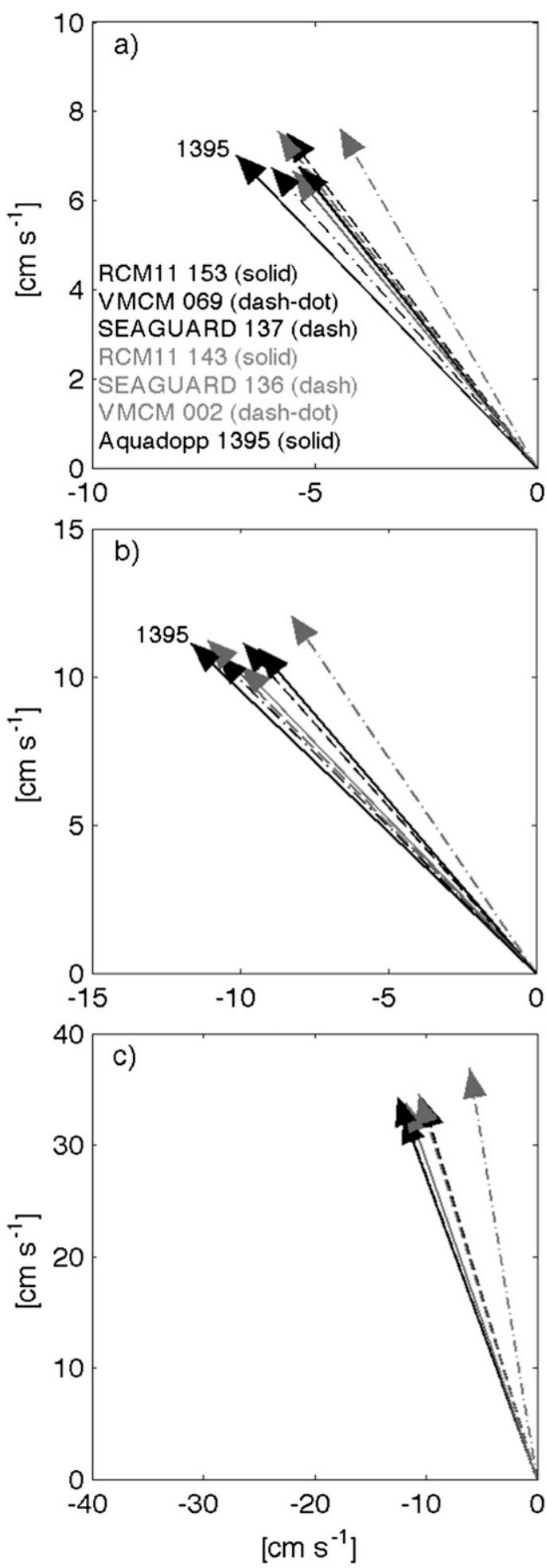

FIG. 4. Time-averaged velocity vectors for (a) common time period (days 327-525), (b) first high-speed event (days 361-382), and (c) highest-speed event (days 565-572). Table 3 lists the data shown in (a). The Aquadopp SN 1395 identifies its vector in (a) and (b). The Aquadopp had stopped before the highest speed event in (c).
During two high-speed events lasting 21 (days 361382 ) and 7 (days 565-572) days with mean speeds of approximately 15 and $36 \mathrm{~cm} \mathrm{~s}^{-1}$, respectively, RCM11 speeds were lower than the median by $4 \%$ and $2 \%$, respectively, while SEAGUARD speeds were 3\% higher than and identical to the median, respectively (Figs. $4 \mathrm{~b}$ and $4 \mathrm{c}$ ). The Aquadopp speed remained higher than the median by about $7 \%$ during the first high-speed event (Fig. 4b), but the Aquadopp had stopped before the second event (Fig. 4c).

Direction differences between RCM11 and SEAGUARD same-model pairs increased during the first high-speed event to $3^{\circ}$, and with the exception of VMCM 002 all mean-current directions were within $3^{\circ}$ of the median. The highest speed event yielded the least deviation in current direction. Again, excluding VMCM 002 , all directions were within $2^{\circ}$ of the median and the RCM11 and SEAGUARD pairs agreed within $1^{\circ}$.

\section{b. Regression analysis}

\section{1) SAME-MODEL PAIR COMPARISONS}

A close comparison of same-model pairs is provided by scatterplots of current-speed measurements in Figs. 5a-d and the difference in current direction (deeper minus shallower direction) versus speed of the deeper current meter of each pair in Figs. 5e-h. The black asterisks in Figs. 5e-h are the median direction difference calculated for $2 \mathrm{~cm} \mathrm{~s}^{-1}$ speed bins. Linear, least squares fits were computed for the comparisons and tabulated statistics are shown in Figs. 5a-d.

The speed comparisons agree well within same-model pairs, producing correlations $R^{2}$ of $0.98-0.99$ for all comparisons. VMCM speeds agree with unity slope within $1 \%$. The same-model speed comparisons for SEAGUARD measurements agree with unity slope within $2 \%$. The RCM11 measurements agree with unity slope within $2 \%$.

Direction differences are greatest at low current speeds, particularly for the VMCM. The shape and magnitude of these direction differences versus speed scatterplots can be simply explained as resulting from a standard deviation in each of the two orthogonal measurements of current vector components of $\delta u_{1} \sim 0.7 \mathrm{~cm} \mathrm{~s}^{-1}$. By simple propagation of error, we estimate

$$
\delta \theta \sim \sqrt{2} \frac{\delta u_{1}}{U} \times \frac{180}{\pi}
$$

expressed in degrees for a single current meter. As the current magnitude $U$ decreases, the angle error $\delta \theta$ increases. For two current meters measuring components independently, the difference is $\delta u_{\text {diff }} \sim \sqrt{2} \delta u_{1}$, so 
TABLE 3. Time-averaged statistics for common period (days 327-525). The variables $u$ and $v$ are vector averaged. Speed and direction were calculated from the vector-averaged $u$ and $v$, respectively. Direction is clockwise from magnetic north. To account for magnetic declination at this site and date, add $9.6086^{\circ}$ to these values. Values correspond to vectors plotted in Fig. 4a. (bottom row) The median of the mean values in the column above it. (rightmost column) The ratio of the median of mean speeds to each respective mean speed.

\begin{tabular}{|c|c|c|c|c|c|c|c|c|}
\hline Level & Type & $\mathrm{SN}$ & Pressure (dbar) & $u\left(\mathrm{~cm} \mathrm{~s}^{-1}\right)$ & $v\left(\mathrm{~cm} \mathrm{~s}^{-1}\right)$ & Speed $\left(\mathrm{cm} \mathrm{s}^{-1}\right)$ & Direction $\left({ }^{\circ}\right)$ & Ratio \\
\hline 1 & RCM11 tilt correction off & 153 & - & -5.34 & 6.76 & 8.61 & 321.7 & 1.05 \\
\hline 2 & VMCM & 069 & - & -5.97 & 6.75 & 9.01 & 318.5 & 1.00 \\
\hline 3 & SEAGUARD tilt correction on & 137 & 4016.2 & -5.63 & 7.52 & 9.40 & 323.2 & 0.96 \\
\hline 4 & RCM11 tilt correction on & 143 & - & -5.47 & 6.66 & 8.62 & 320.6 & 1.05 \\
\hline 5 & SEAGUARD tilt correction off & 136 & 4028.7 & -5.82 & 7.55 & 9.54 & 322.4 & 0.94 \\
\hline 6 & VMCM & 002 & - & -4.43 & 7.63 & 8.82 & 329.8 & 1.02 \\
\hline \multirow[t]{2}{*}{7} & Aquadopp & 1395 & 4030.8 & -6.75 & 7.01 & 9.73 & 316.1 & 0.93 \\
\hline & Median & - & - & - & - & 9.01 & 321.7 & - \\
\hline
\end{tabular}

$$
\delta \theta_{\text {diff }} \sim 2 \frac{\delta u_{1}}{U} \times \frac{180}{\pi}
$$

Because this estimate works well, we do not have to speculate whether the ocean currents or the mooring may introduce any added angle variation at low current speeds.

Figures $5 \mathrm{c}$ and $5 \mathrm{~g}$ compare the VMCM data after excising all 30-min intervals in which any one of the four rotors stalled for even one minute. Individual rotors stalled during $1 \%-7 \%$ of the 1 -min sample intervals, presumably depending mainly upon the relative orientation of the current meter housing. The fraction of 30-min intervals unaffected by any stall of any single rotor during any 1 -min subinterval was greater than $70 \%$. The slightly curved deviation from constant angle offset remains the same (Fig. 5g), and most notably the scatter is greatly reduced in direction differences, which had been largest for low current speeds. The VMCM current speeds continue to agree with unity slope within $1 \%$.

\section{2) DIFFERENT-MODEL PAIR COMPARISONS}

A close comparison for current-speed measurements of the different-model pairs is provided by the scatterplots in Figs. 6a-f and for direction difference as a function of speed in Figs. 6g-1. The VMCM measurements were placed on the abscissa, so that a slope $>1$ or $<1$ tells whether the comparison current meter increases faster or slower than the test record that had median vector magnitude. Each plot uses the maximum coincident time series available for each respective pair of instruments.

The slopes reported here are of the fitted line. Close examination shows that the lines do not always pass through the origin, and consequently the slopes are not the same as the ratio of speeds. The ratio of speeds would therefore change slightly for different ranges of speed. With this caveat, we summarize the line slopes in the comparisons of the panels in Fig. 6. The slope for
RCM11 153 is $6 \%$ lower than VMCM 069 (slope 0.94), essentially the same as SEAGUARD 136 (slope 1.00), and 9\% lower than the Aquadopp (slope 1.09). SEAGUARD 136 speeds are higher than VMCM 069 in the low range and agree well in the high range (slope 0.95); SEAGUARD speeds are 7\% lower than the Aquadopp (slope 1.07). The Aquadopp slope is $2 \%$ higher than VMCM 069 (slope 1.02) for speeds up to $\sim 40 \mathrm{~cm} \mathrm{~s}^{-1}$. The $R^{2}$ values are high $(\geq 0.97)$ for all intercomparisons.

The scatterplots of the difference in current direction versus speed for one current meter of each pair (Figs. $6 g-1)$ all exhibit similar amounts of direction scatter, and in all cases the direction scatter decreases with increasing current speed (consistent with the preceding explanation). The mean direction for VMCM 069 is offset a few degrees to the left $\left(2^{\circ}-4^{\circ}\right)$ of the RCM11 and SEAGUARD, and a few degrees to the right of the Aquadopp, consistent with the time-mean vector comparison (Fig. 4). The mean direction for the Aquadopp is a few degrees to the left of all other instruments, and the RCM11 and SEAGUARD mean directions agree within about $1^{\circ}$ of each other-again, consistent with the time-mean vector comparisons.

\section{c. Response analysis}

In addition to the above-mentioned regression analyses, response functions were calculated between pairs of current meters using their $u$ and $v$ current components. Emery and Thomson (2001) discuss linear transfer functions, and the calculation is implemented in a Matlab-supplied routine, tfestimate.m. The window length selected for these analyses was 100 points $(50 \mathrm{~h})$ to smooth the response functions by averaging over many ensemble members. At periods longer than 5-10 h, the ensemble-averaged admittance magnitudes reached a plateau, near unity (Figs. 7 and 8). We also examined the results from longer windows and longer periods, such as 10 and 40 days (not included here), and verified that 

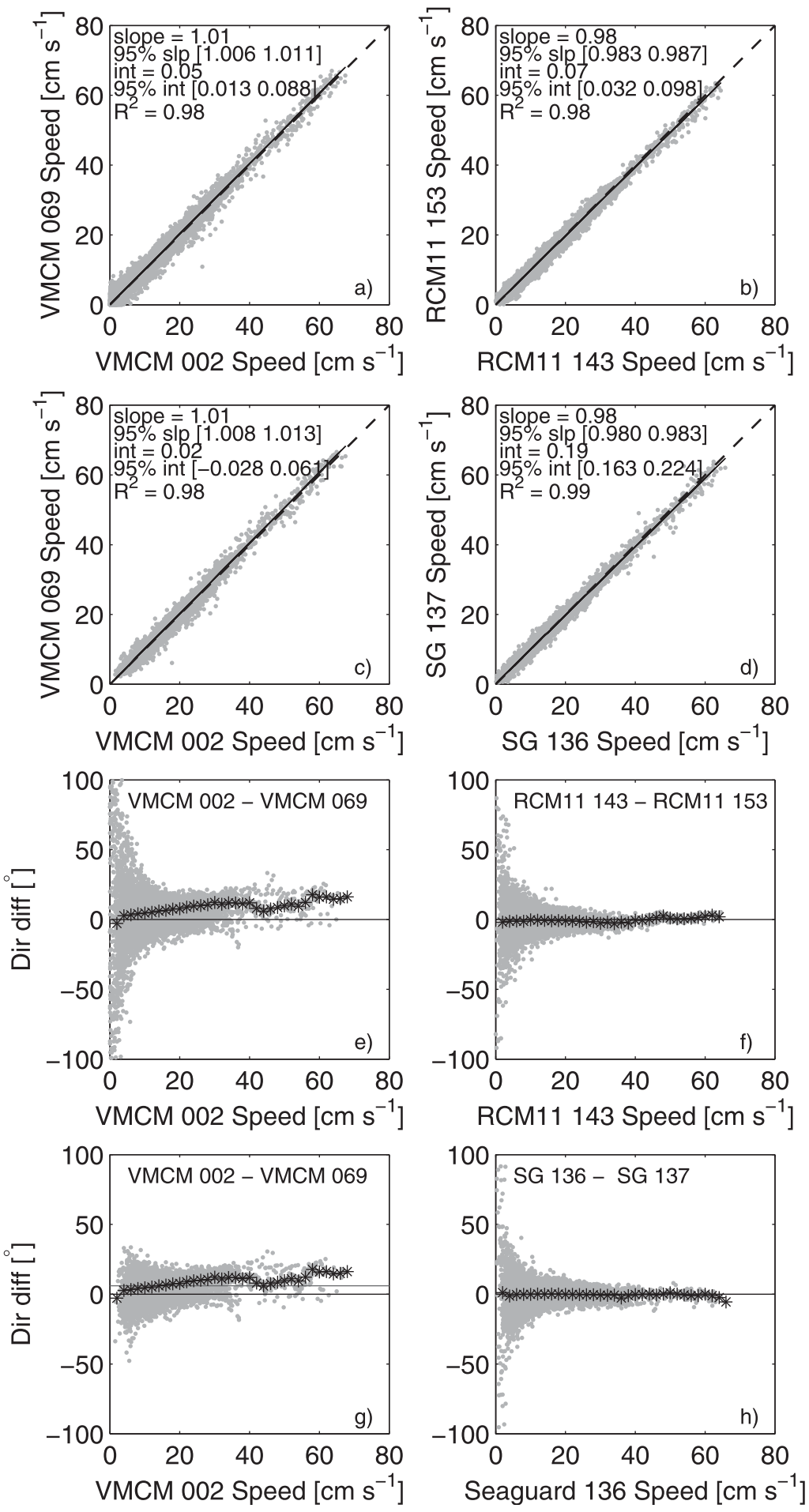

FIG. 5. Scatterplots of current speed for same-model current meter pairs: (a) VMCM, (b) RCM11, (c) VMCM with rotor stalls excised, and (d) SEAGUARD. For each pair in (a)-(d), the deeper (shallower) current meter speed is plotted on the $x$ axis ( $y$ axis). The dashed black line has a slope of one. The solid black line is the fit to the data. The slope and intercept of the solid black line and their confidence intervals are listed in the top-left corner of each plot. Scatterplots of the difference in current direction as labeled vs speed of the deeper current meter of each same-model pair: (e) VMCM, (f) RCM11, (g) VMCM with rotor stalls excised, and (h) SEAGUARD. The asterisks represent the median difference calculated for $2 \mathrm{~cm} \mathrm{~s}^{-1}$ bins. 


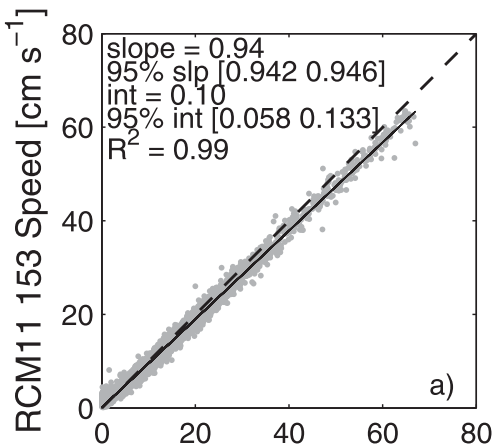

VMCM 069 Speed $\left[\mathrm{cm} \mathrm{s}^{-1}\right.$ ]

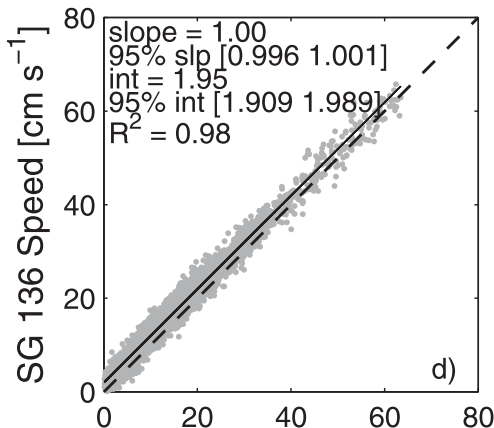

RCM11 153 Speed $\left[\mathrm{cm} \mathrm{s}^{-1}\right.$ ]

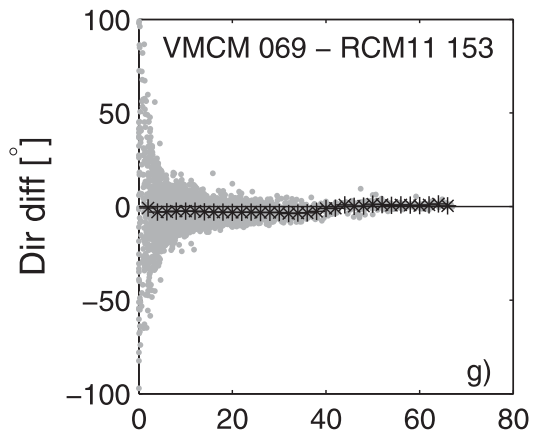

VMCM 069 Speed $\left[\mathrm{cm} \mathrm{s}^{-1}\right.$ ]

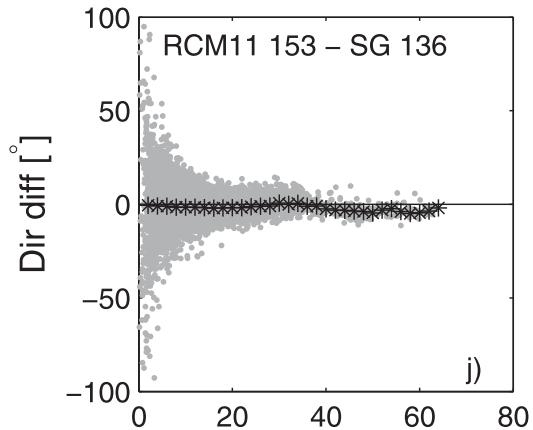

RCM11 153 Speed $\left[\mathrm{cm} \mathrm{s}^{-1}\right.$ ]

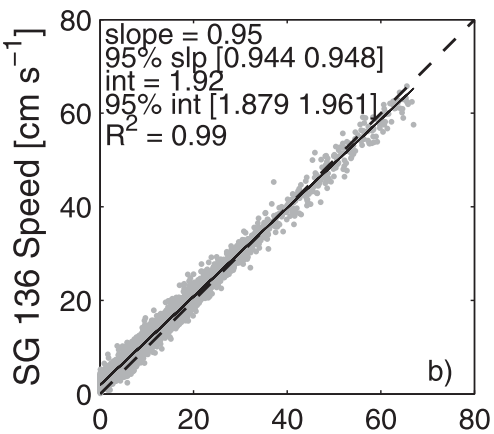

VMCM 069 Speed $\left[\mathrm{cm} \mathrm{s}^{-1}\right.$ ]

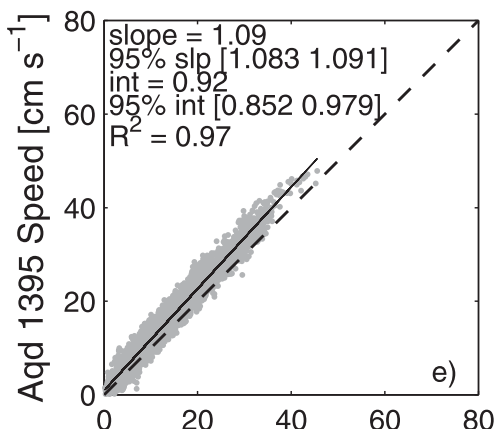

RCM11 153 Speed $\left[\mathrm{cm} \mathrm{s}^{-1}\right.$ ]

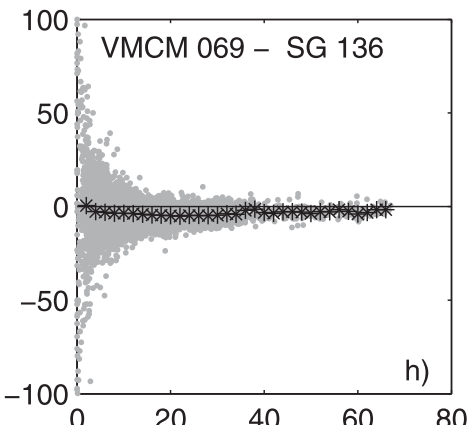

VMCM 069 Speed $\left[\mathrm{cm} \mathrm{s}^{-1}\right.$ ]

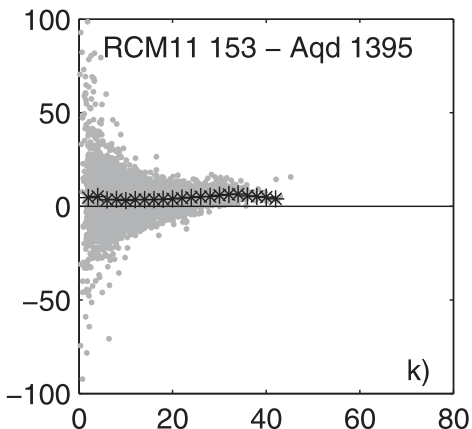

RCM11 153 Speed $\left[\mathrm{cm} \mathrm{s}^{-1}\right.$ ]

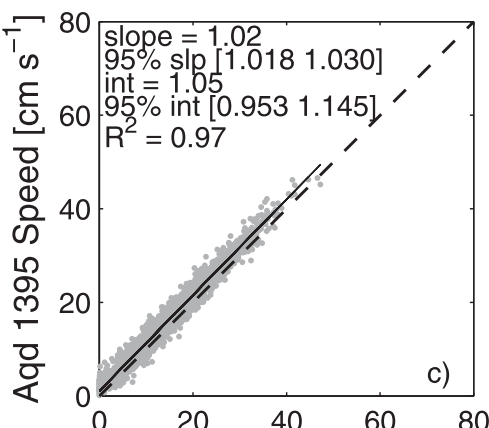

VMCM 069 Speed $\left[\mathrm{cm} \mathrm{s}^{-1}\right.$ ]

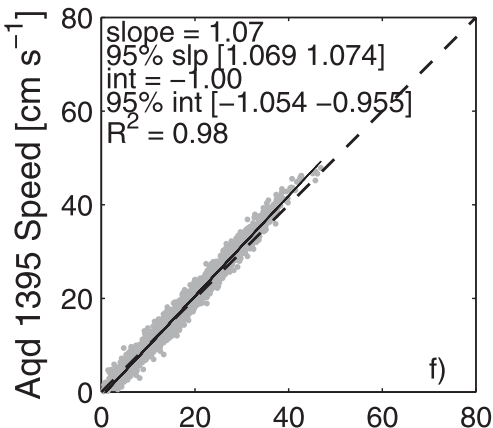

SG 136 Speed [ $\mathrm{cm} \mathrm{s}^{-1}$ ]

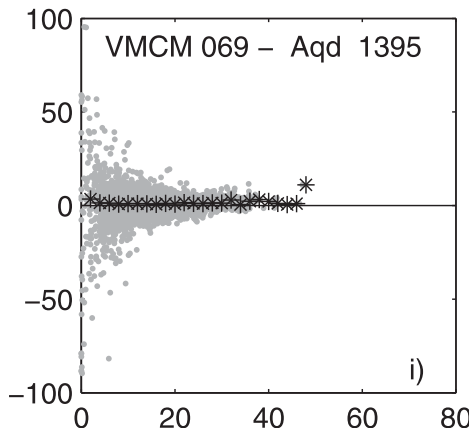

VMCM 069 Speed $\left[\mathrm{cm} \mathrm{s}^{-1}\right.$ ]

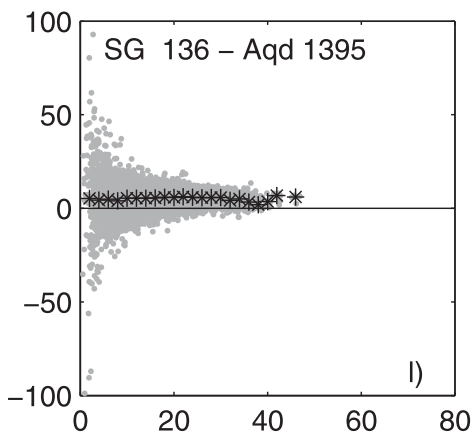

SG 136 Speed $\left[\mathrm{cm} \mathrm{s}^{-1}\right.$ ]

FIG. 6. (a)-(f) Scatterplots of current speed for different-model pairs for all coincident data. The dashed black line has a slope of one. The solid black line is the fit to the data. The Aquadopp pairings span a lower range of speeds because the Aquadopp stopped before the highest current-speed event. The slope and intercept of the black line and their confidence intervals are listed in the top-left corner of each plot. (g)-(1) Scatterplots of the difference in current direction vs speed for all coincident data. The asterisks represent the median difference calculated for $2 \mathrm{~cm} \mathrm{~s}^{-1}$ bins. 

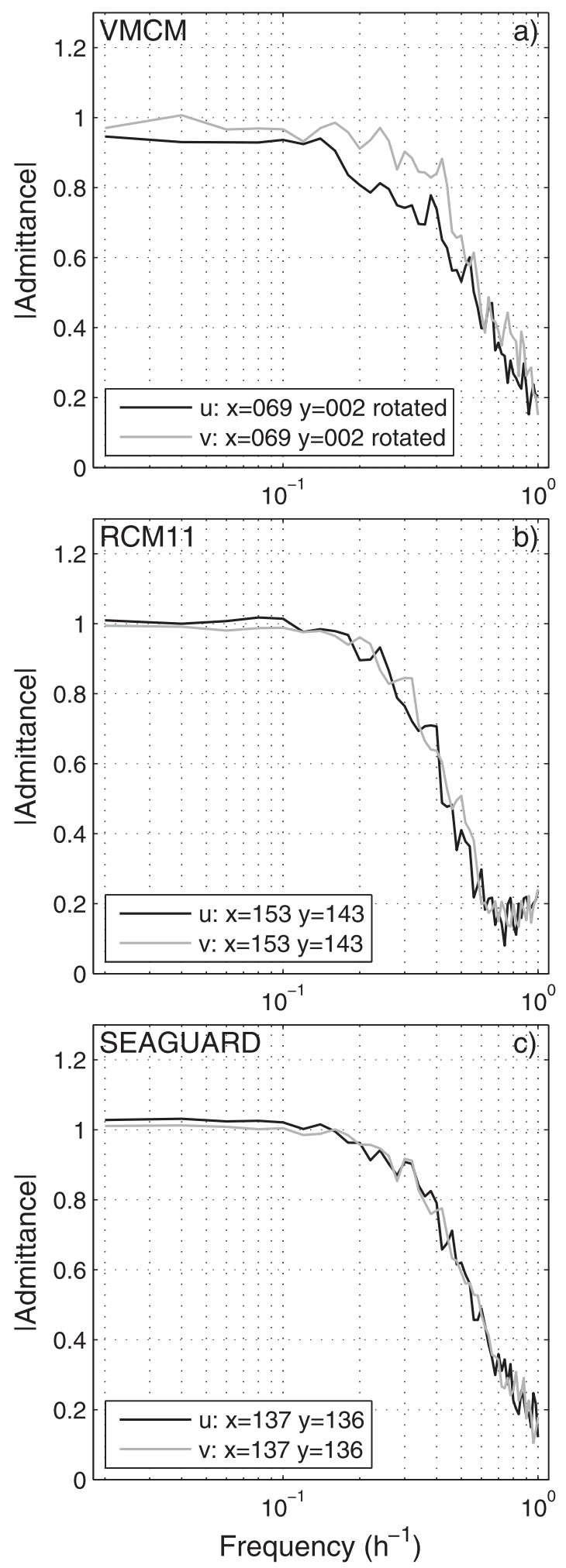

FIG. 7. Admittance magnitude for same-model pair $u$ and $v$ components. VMCM 002 direction was rotated $8^{\circ}$ to the left to partially compensate for its compass offset (see text). (a) VMCM, (b) RCM11, and (c) SEAGUARD. the plateau of admittance magnitude extended to those longer periods.

This analysis was applied to the three same-model pairs for the common time period (Fig. 7). Their speed records were already known to be nearly identical, and we wanted to examine at what higher range of frequencies the response functions differed significantly from unity. For this analysis the VMCM 002 direction was rotated $8^{\circ}$ to the left (the mean angle offset) and then speed and direction were converted back to $u$ and $v$. However, this mean rotation was only a partial fix, because the compass offset of VMCM 002 depended on current direction [compared to the other current meters, as shown in Kennelly et al. (2012)]. While the speed measurements of VMCM 002 were good (Fig. 5), its compass had problems and this is a likely explanation for why the response functions in Fig. 7a are slightly less than 1. Therefore, we chose VMCM 069 for all further comparisons. At periods shorter than $5 \mathrm{~h}$, the response magnitudes fall off rapidly. We interpret that drop as a signature of real differences in the turbulent currents between their nearby locations on the mooring.

Using the same procedure, we applied response analyses to different-model pairs for the common time period. In this case (Fig. 8) the admittance magnitudes reached plateaus slightly offset from unity for long periods $(>5$ $10 \mathrm{~h}$, as above), indicating a current-speed bias between the instruments. The $u$ and $v$ admittances were consistent. Plateau heights remained the same when the response analysis was performed on the higher-speed event. While those admittance curves were bumpier because of less averaging, the levels stayed about the same.

The response admittance magnitudes agree well with the vector-averaged speed ratios, and moderately well with the inversed slope of the instantaneous speed scatterplots, all of which are summarized in Table 4 and discussed next.

\section{d. Summary of comparisons}

Current-speed measurements in general agreed well among all the instruments. Two types of same timeinterval comparisons were conducted:

1) mean-current magnitudes after vector averaging over three separate time intervals:

(i) 198-day common time interval,

(ii) a 21-day high-speed event, and

(iii) a 7-day highest-speed event;

2) current measurements at 30-min sampling intervals:

(i) calculating the slopes of current-speed scatterplots, and

(ii) calculating the ensemble-averaged admittance magnitude for $u$ and $v$ components. 
VMCM/RCM11

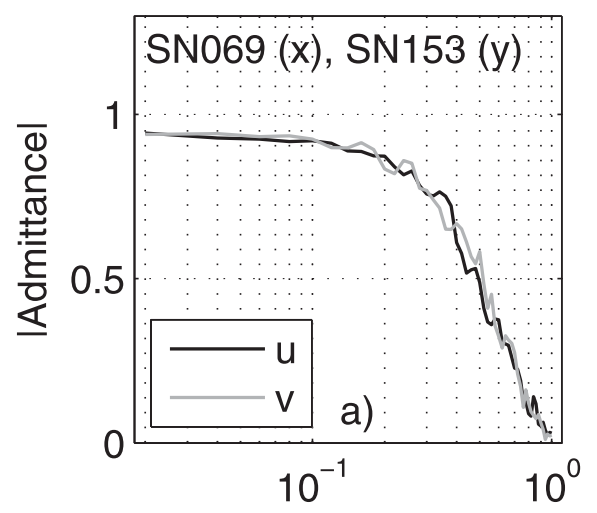

RCM11/Seaguard

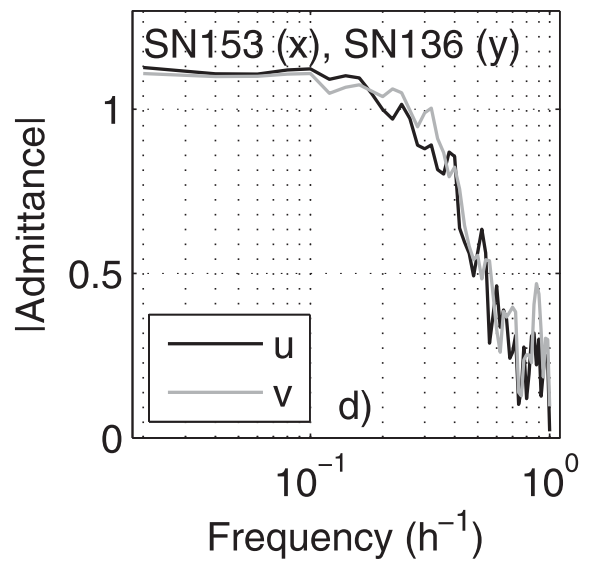

VMCM/Seaguard

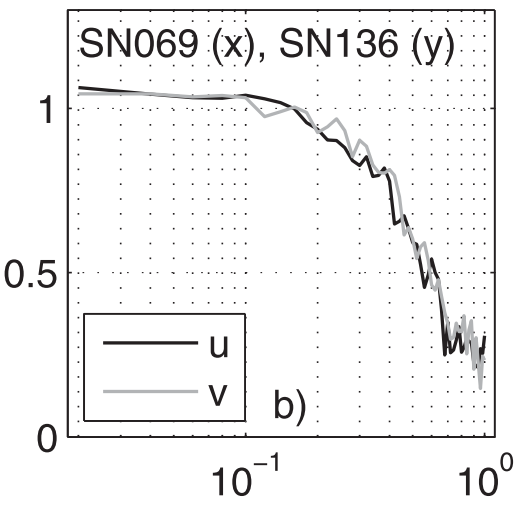

RCM11/Aquadopp

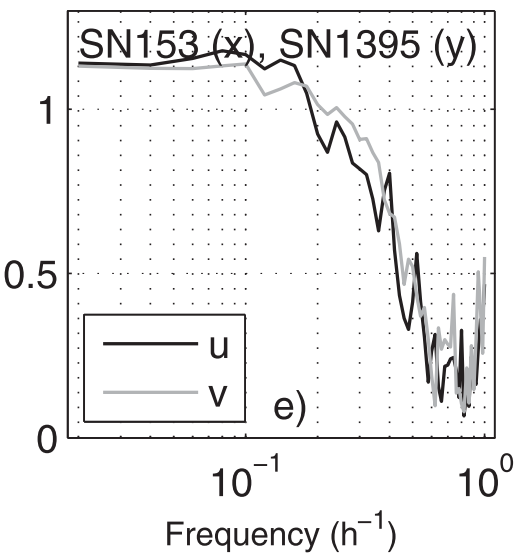

VMCM/Aquadopp
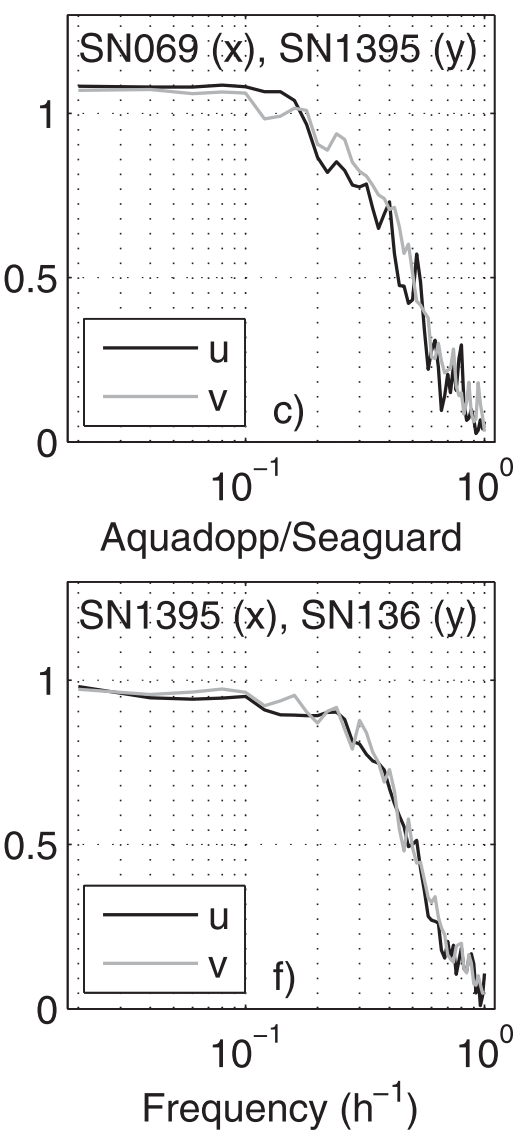

FIG. 8. Admittance magnitude for different-model pair $u$ and $v$ components for the common time interval. VMCM 069 is compared to (a) RCM11153, (b) SEAGUARD 136, and (c) Aquadopp. RCM11 153 is compared to (d) SEAGUARD 136 and (e) Aquadopp, and (f) Aquadopp is compared to SEAGUARD 136.

The findings from the comparisons are summarized in Table 4. The vector-mean findings [1(i)-(iii)] and lowfrequency admittance findings [2(ii)] are summarized in the rightmost columns. Care must be taken when interpreting the scatterplots [2(i)]; because the fitted line does not pass through the origin, the slopes are not proportionality factors.

The three pairs of same-model current meters (top of Table 4) have consistent vector-averaged speeds within $2 \%$, and the departures are insignificant within model type. The VMCMs are at the median vector magnitude speed for all three time intervals and speed-range measurements (Table 3). These median measurements of the currents are used for subsequent intermodel comparisons.

Referring to the bottom of Table 4, the RCM11s produced vector-mean speeds that were about $5 \%$ low in low-speed ranges (average 9 and $15 \mathrm{~cm} \mathrm{~s}^{-1}$ for 198 days and 21 days, respectively) and agreed with the median VMCM records within 2\% for the highest-speed event. Consequently, while one may choose to increase the RCM11 speeds by $5 \%$ in the lower ranges, it is not appropriate to do so for the high range. The summary speed-correction ratio (and its uncertainty) for RCM11s is $1.04(-0.02 /+0.02)$.

The SEAGUARDs produced vector-mean speeds that were $0 \%-5 \%$ higher than the median (VMCM) records in the different speed ranges. The scatterplot against the VMCM supports the indication that agreement improves to near unity with increasing speed. The summary speed-correction ratio (and its uncertainty) for SEAGUARDs is $0.97(-0.02 /+0.03)$.

The Aquadopp produced vector-mean speeds that were about $7 \%$ higher than the median (VMCM) records in both the common time interval and in the first high-speed event. (Recall its battery had drained before the highest-speed event.) Because its fitted line on the scatterplot (Fig. 6c) is 1-2 $\mathrm{cm} \mathrm{s}^{-1}$ above the 1:1 line, with 


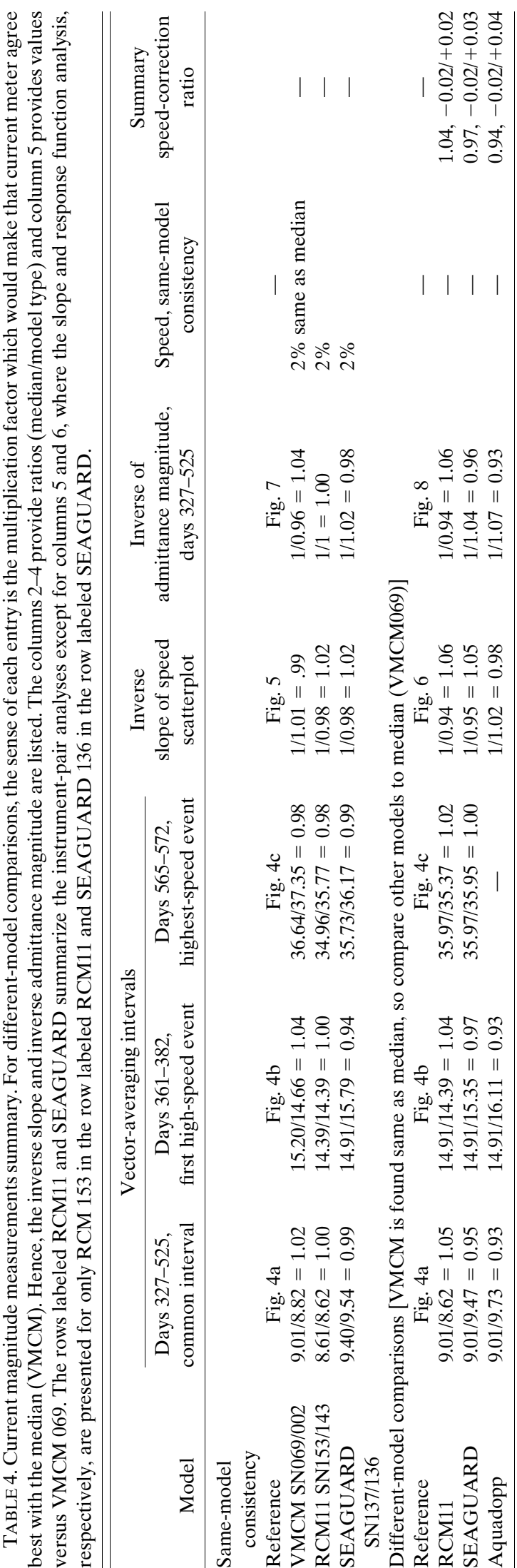

a slope of 1.02 (with inverse $1 / 1.02=0.98$ ), one might not want to apply a factor of 0.93 to Aquadopp currents at the higher ranges (particularly because only one Aquadopp was tested). This reasoning led to our summary speed-correction ratio for the Aquadopp of 0.94 $(-0.02 /+0.04)$, in which the uncertainty range has been increased. In general agreement with this summary, A. Houk and W. Johns (2012, unpublished manuscript) found that the Aquadopp tended to read between 0.5 and $2.5 \mathrm{~cm} \mathrm{~s}^{-1}$ higher than the SEAGUARD, and like our Fig. $6 f$ the slope was greater than 1 .

Current-direction measurements improved in agreement between instruments with increasing current speed. This is consistent with simple propagation of error for $(u, v)$ measurements each having $\sim 0.7 \mathrm{~cm} \mathrm{~s}^{-1}$ noise. At speeds below $5 \mathrm{~cm} \mathrm{~s}^{-1}$, there was a great deal of scatter in angle $\left(\sim 15^{\circ}\right.$ standard deviation), whether comparing same- or different-model current meters. Current angle differences decrease to $\sim 5^{\circ}$ standard deviation at $10 \mathrm{~cm} \mathrm{~s}^{-1}$ speeds, and smaller yet $\left(\sim 2^{\circ}\right)$ for speeds above $20 \mathrm{~cm} \mathrm{~s}^{-1}$. Vector-averaged current direction over the common time period showed good agreement with the median direction within $\pm 3^{\circ}$, consistent with manufacturer specifications, with two exceptions: The compass of VMCM 002 appears faulty with $8^{\circ}$ offset to the right, and the Aquadopp had $6^{\circ}$ offset to the left of the median of the others. A. Houk and W. Johns (2012, unpublished manuscript) also found the Aquadopp had a slight offset of from about $-2^{\circ}$ to $-4^{\circ}$ relative to the SEAGUARD.

\section{Conclusions}

A deep ocean mooring was deployed for 11 months in Drake Passage to intercompare velocity measurements from four models of current meter. All seven current meters returned good data for a 198-day period over which to intercompare their records.

All measurements of current speed agreed within 7\%, but the differences depend upon speed range:

- at low speeds $\left(<35 \mathrm{~cm} \mathrm{~s}^{-1}\right)$, compared to the median (VMCM record), the RCM11s were 5\% low, the SEAGUARDs were $5 \%$ high, and the Aquadopp was $7 \%$ high; and

- in the highest-speed event (7 days ranging to $67 \mathrm{~cm} \mathrm{~s}^{-1}$ ), the RCM11 and SEAGUARD and VMCM current speeds all agreed within $2 \%$.

The results of this study indicate that no speedcorrection factor should be applied to high-speed data recorded by RCM11 and SEAGUARD current meters. For speeds less than $35 \mathrm{~cm} \mathrm{~s}^{-1}$ measured by RCM11s, a factor near 1.05 would not be inappropriate. However, 
we choose not to apply this factor, because the effect is lower than the differences found by Hogg and Frye (2007) and would make corrections that are barely above the usual expected current meter uncertainties.

Acknowledgments. We gratefully acknowledge the crew of RV/IB Nathaniel B. Palmer and the team of technicians from the Raytheon Polar Sciences group for their willingness and competent efforts during the deployment and recovery cruises. Erran Sousa at URI deserves particular acknowledgment for the successful recovery of the mooring, reestablishing acoustic transponding with it after a worrisome interval of several hours when all communication had been lost while it rose and floated on the surface in thick fog conditions. At WHOI we wish to thank Rick Trask and Ruthanne Molineaux and the Rigging Shop for mooring preparation, Scott Worrilow and Sean Patrick Whelan for instrument preparation, Nan Galbraith for reading the binary VMCM files and converting them to MATLAB, and Geoff Allsup for advice regarding the VMCMs. At AADI we wish to thank Brandon Reiff, Richard Butler, and Anders Tengberg. At Nortek we wish to thank Malcolm Williams, Eric Siegel, and Atle Lohrmann. We thank Adam Houk and William Johns at the University of Miami for sharing the results of their current meter intercomparison. We thank Mark Wimbush for the helpful discussions regarding the data records. We appreciate the constructive comments from our reviewers. This work was supported by U.S. National Science Foundation Grants ANT-0635437 and ANT-0636493.

\section{REFERENCES}

Chereskin, T. K., K. A. Donohue, D. R. Watts, K. L. Tracey, Y. L. Firing, and A. L. Cutting, 2009: Strong bottom currents and cyclonesis in Drake Passage. Geophys. Res. Lett., 36, L23602, doi:10.1029/2009GL040940.

Dickey, T. D., A. J. Plueddemann, and R. A. Weller, 1998: Current and water property measurements in the coastal ocean. The Global Coastal Ocean, K. H. Brink and A. R. Robinson, Eds., The Sea, Vol. 13, John Wiley and Sons, 367-398.

Emery, W. J., and R. E. Thomson, 2001: Data Analysis Methods in Physical Oceanography. Elsevier, 658 pp.

Ferrari, R., C. Provost, A. Renault, N. Sennchael, N. Barr, Y.-H. Park, and J. H. Lee, 2012: Circulation in Drake Passage revisited using new current time series and satellite altimetry: 1. The Yaghan Basin. J. Geophys. Res., 117, C12024, doi:10.1029/ 2012JC008264

Hogg, N. G., and D. E. Frye, 2007: Performance of a new generation of acoustic current meters. J. Phys. Oceanogr., 37, 148-161.

Kennelly, M. A., D. R. Watts, K. L. Tracey, and K. A. Donohue, 2012: An intercomparison of four models of current meter in high current conditions in Drake Passage. University of Rhode Island Graduate School of Oceanography Tech. Rep. 12-04, 82 pp. [Available online at http://digitalcommons.uri. edu/physical_oceanography_techrpts/3/.]

Smith, W. H. F., and D. T. Sandwell, 1997: Global sea floor topography from satellite altimetry and ship depth soundings. Science, 277, 1956-1962, doi:10.1126/science.277.5334.1956.

Victoria, I., 2011: Measuring currents in demanding environments with a Seaguard RCM. 2011 IEEE/OES/CWTM Tenth Working Conference on Current, Waves and Turbulence Measurement (CWTM), J. Rizoli White and A. J. Williams III, Eds., IEEE, 237-245

Weller, R. A., and R. E. Davis, 1980: A vector measuring current meter. Deep-Sea Res., 27A, 565-566, IN1-IN2, 567-581, doi:10.1016/0198-0149(80)90041-2. 